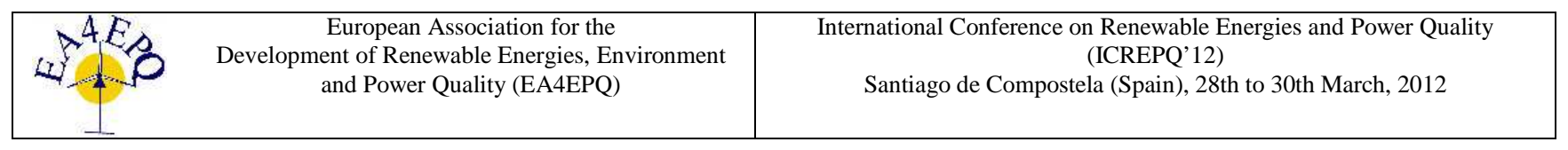

\title{
Simulink Based Model of PV Plant
}

\author{
Silvano Vergura \\ Department of Electrotechnics \\ Politecnico di Bari, \\ St. E. Orabona, 4, 70125 Bari (Italy) \\ Phone/Fax number:+0039 080 5963590, e-mail: vergura@poliba.it
}

\begin{abstract}
The paper proposes the Simulink based model of a gridconnected PV plant. The model considers standard monocrystalline PV modules, even if any typology of sylicon based PV module can be used, because the values of the technical specifications can be easily modfied by the user by means of masks. The proposed model considers a multi-inverter PV plant with local MPPT, implementing the Perturbe and Observe strategy. Moreover, also the models of the interface protection device, of the coupling capacitor and of the L-filter have been implemented, allowing to modify the characteristic values. Several simulation results are presented in this paper and they agree with the expected values.
\end{abstract}

\section{Key words}

PV plant, Simulink, modeling, mask.

\section{Introduction}

After the Commission of the European Communities has published the green paper [1] where is stated the target of $20 \%$ of produced energy by Renewable Energy Sources (RES) within 2020, all the EU countries are focusing special attention on RES. However some technical problems are still open and the researchers are studying them by means of pilot projects, experiments and simulation tools. Specifically, some specific issues for PhotoVoltaic (PV) plants as Maximum Power Point Tracking (MPPT), anti-islanding strategies and so on are usually studied by means of the simulation before implementing them in real PV plants [2]. Several simulation tools are used to model a whole PV plant or its parts: PSCAD, CASPOC, PSPICE, PSIM, MATAL/SIMULINK [3]. The last one, for example, is used to model a single-phase grid-connected PV plant, taking into account the aforementioned issues [4]. This paper deals with the modeling of a three-phase gridconnected PV plant, implementing also the interface protection device, needed to power down the PV plant when an over/under-voltage or an over/under-frequency happens. The proposed model is constituted by several sub-systems; the most parameters of each one of them can be modified by the user before running the simulation. This allows you to use the proposed model for PV systems very different from the one implemented by default and, also, allows to take several information about the operation of the PV plant. In fact, as the PV plant is not modeled as a unique black box but as several interconnected boxes, it is possible to take information by each functional block. This approach allows to model and to simulate a wellworking PV plant as well as several typologies of defects located in different section of a PV plant. The input excitation data are constituted by the environmental temperature and the radiation, while the output data presented in this paper are the voltage, current and power of a single PV sub-array. The paper is organized as follows: Section 2 reports a description of a real $20 \mathrm{kWp}$ multi-inverter PV plant used as reference to build the model. Section 3 presents the Simulink based model of the PV plant described in the previous section. Section 4 presents some simulation results and conclusions are reported in Sec. 5.

\section{Description of a real PV plant}

The proposed model of PV plant is based on a real PV plant; then, this section describes just the real PV plant in the real operation conditions. The successive section proposes the model of this PV plant, implemented in Simulink environment. Real PV plant is a grid-connected PV plant of $19,8 \mathrm{kWp}$ rated power. It consists of six subarrays composed of two parallel connected strings having each of them 22 photovoltaic panels. The nominal power of a single module is $150 \mathrm{Wp}$ whereas the total power amount for a single array is $3300 \mathrm{Wp}$.

For each sub-array a $3000 \mathrm{~W}$ inverter is installed. The system faces the south and is sloped at about $44^{\circ}$.

The installation scheme is depicted in Fig.1, where the six sub-arrays are classified by means of a number, while PV module specifications and inverter specifications are listed in Tab. I and II, respectively. Fig. 2 reports the reduced principle scheme of the PV plant, where the main components of each sub-arrays are considered: PV modules, the Maximum Power Point Tracking (MPPT), the coupling capacitor, the inverter, the filter, the insulation transformer, the interface protection device.

The PV voltage must reach the specified minimum value before the inverter begins to feed the grid. The storage time of the acquisition data system is set to 10 minutes whereas the sample time to 2 seconds. The monitoring system measures and stores daily and cumulative values of total power, generated energy and maximum efficiency. The capacity of the monitoring 
equipment is up to 400 days.

The inverter automatically determines the solar generator MPP voltage, which is defined in the internal regulation system as the desired PV voltage. Moreover the inverters have internal protection systems for decoupling the PV plant from the grid when the grid voltage and the grid frequency exceed the ranges fixed by the technical rule [5].

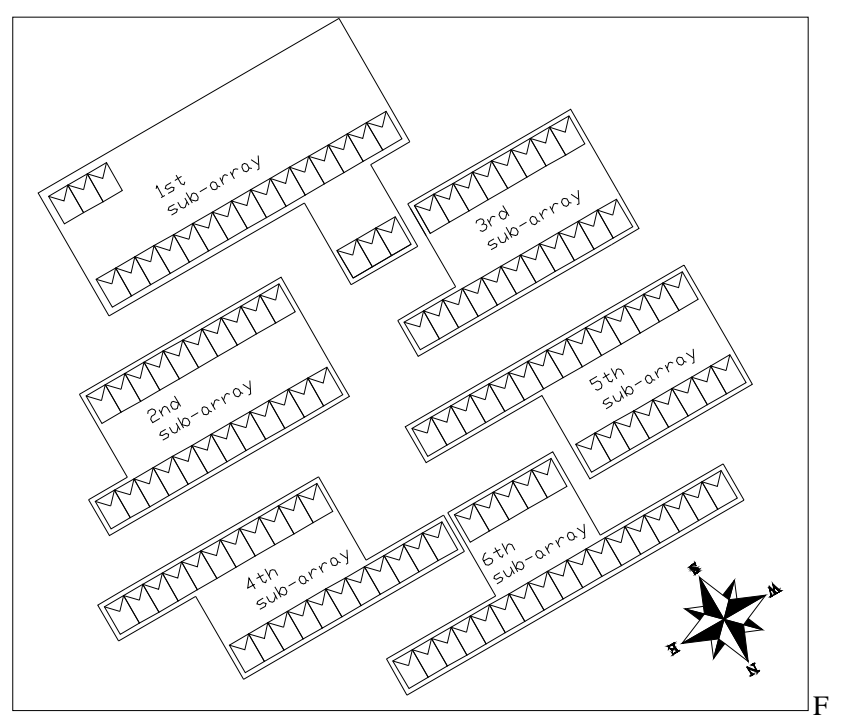

Fig. 1. PV sub-arrays

TAB. I SPECIFICATIONS OF EACH PV MODULE

\begin{tabular}{|l|c|}
\hline Type and manifacturer & Solterra $150 \mathrm{~W}$ \\
\hline Cells & monocrystalline \\
\hline Max power [W] & 150 \\
\hline Min. power [W] & 140 \\
\hline Voltage at typical power [V], $\mathrm{V}_{\mathrm{MPP}}$ & 34.7 \\
\hline Current at typical power [A], I I & 4.32 \\
\hline Open circuit voltage [V], $\mathrm{V}_{\mathrm{oc}}$ & 43.2 \\
\hline Short circuit current [A], $\mathrm{I}_{\mathrm{sc}}$ & 4.7 \\
\hline
\end{tabular}

\begin{tabular}{|l|c|}
\hline NOCT $\left[{ }^{\circ} \mathrm{C}\right]$ & $48^{\circ} \pm 1$ \\
\hline $\begin{array}{l}\text { Number of cells (per module) } \\
\text { Open-circuit voltage thermal } \\
\text { coefficient } \beta\end{array}$ & $-153,1 \mathrm{mV} /{ }^{\circ} \mathrm{C}$ \\
\hline $\begin{array}{l}\text { Short-circuit current thermal } \\
\text { coefficient } \alpha\end{array}$ & $+0,90 \mathrm{~mA} /{ }^{\circ} \mathrm{C}$ \\
\hline
\end{tabular}

TAB. II SPECIFICATIONS OF EACH INVERTER

\begin{tabular}{|l|c|}
\hline \multicolumn{2}{|c|}{ INPUT DATA } \\
\hline Max $\mathrm{P}_{\mathrm{DC}}$ & $3300 \mathrm{~W}$ \\
\hline max $\mathrm{V}_{\mathrm{DC}}$ & $600 \mathrm{~V}$ \\
\hline Voltage range, MPPT $\left(\mathrm{V}_{\mathrm{MPP}}\right)$ & $268 \mathrm{~V}-600 \mathrm{~V}$ \\
\hline Max input current $\left(\mathrm{I}_{\mathrm{FV} \max }\right)$ & $12 \mathrm{~A}$ \\
\hline Voltage ripple $\left(\mathrm{V}_{\mathrm{PP}}\right)$ & $310 \%$ \\
\hline $\begin{array}{l}\text { max number of parallel-connected } \\
\text { strings }\end{array}$ & Diode \\
\hline Protection for the reverse polarity & $3000 \mathrm{~W}$ \\
\hline \multicolumn{2}{|c|}{ OUTPUT DATA } \\
\hline Max $\mathrm{P}_{\mathrm{CA}}$ & $2750 \mathrm{~W}$ \\
\hline Rated power $\left(\mathrm{P}_{\mathrm{CAnom}}\right)$ & $<4 \%$ \\
\hline THD CA & $220 \mathrm{~V}-240 \mathrm{~V}$ \\
\hline Nominal Voltage CA $\left(\mathrm{V}_{\mathrm{CAnom}}\right)$ & $50 \mathrm{~Hz} / 60 \mathrm{~Hz}$ \\
\hline Frequency & $95,0 \%$ \\
\hline \multicolumn{1}{|c|}{ EFFICIENCY } \\
\hline Max efficiency \\
\hline European efficiency
\end{tabular}

\section{Simulink based model of the PV plant}

The Simulink components have been joined as reported in the scheme of the Fig. 2; then, for each block of Fig. 2 it has been created a mask where the input data can be inserted and/or modified before running new simulations.

Let us analyze each block of one sub-array of Fig. 2 . Each sub-array of PV modules is constituted by 2 parallel-connected strings, each one of them having 11 PV modules.

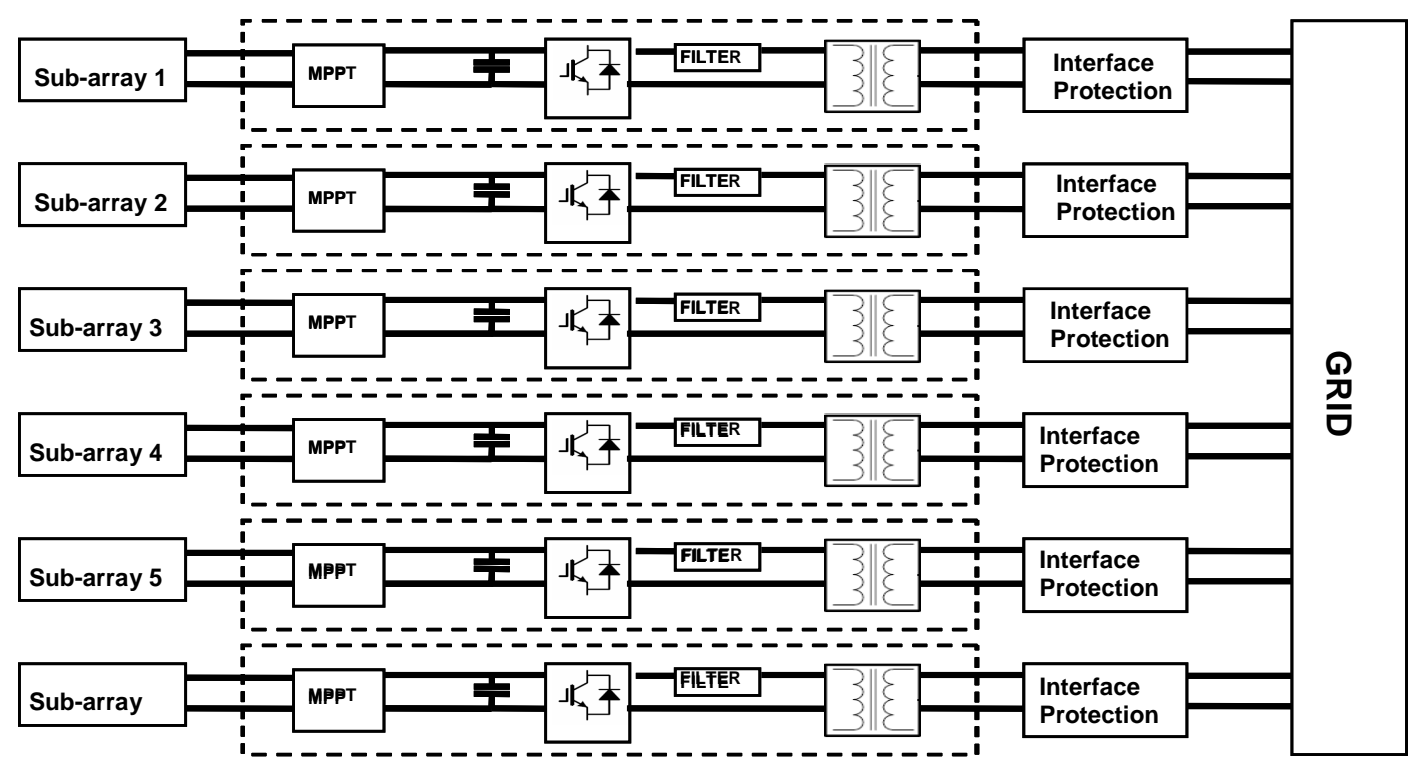

Fig. 2. Reduced principle scheme of the PV plant 
Then, following equations are considered:

$$
\begin{gathered}
V_{s u b}=N_{s m} * V_{M P P}=11 * 34.7 \cong 382 \mathrm{~V} \\
I_{s u b}=N_{p s} * I_{M P P}=2 * 4.32 \cong 8,64 \mathrm{~A} \\
P_{s u b}=V_{s u b} * I_{s u b} \cong 3300 \mathrm{~W}
\end{gathered}
$$

where $\mathrm{N}_{\mathrm{sm}}$ represents the number of series-connected modules, $\mathrm{N}_{\mathrm{ps}}$ the number of parallel-connected strings, $V_{M P P}$ and $I_{M P P}$ the maximum values of voltage and current of each module, respectively, and finally $\mathrm{V}_{\text {sub }}, \mathrm{I}_{\text {sub }}, \mathrm{P}_{\text {sub }}$ the values of voltage, current and power of the whole subarray.

The I-V curve of each PV sub-array is the following:

$$
I_{P V}=I_{s c} \cdot N_{p s} \cdot\left\{1-C_{1}\left[e^{\left(\frac{V_{P V}}{N_{s m} C_{2} V_{o c}}\right)}-1\right]\right\}
$$

where the parameters $I_{s c}$ and $V_{o c}$ are reported in Tab. I, while $C_{1}$ and $C_{2}$ depend on the PV module specifications; in this case $C_{1}=2420$ and $C_{2}=0.078$. Fig. 3 is the mask of the Function block representing each single sub-array. The default values are referred to the PV plant described in Section 2, then the technical specifications of the PV modules are those reported in Tab. I, but they can be modified for PV plants with different specifications.

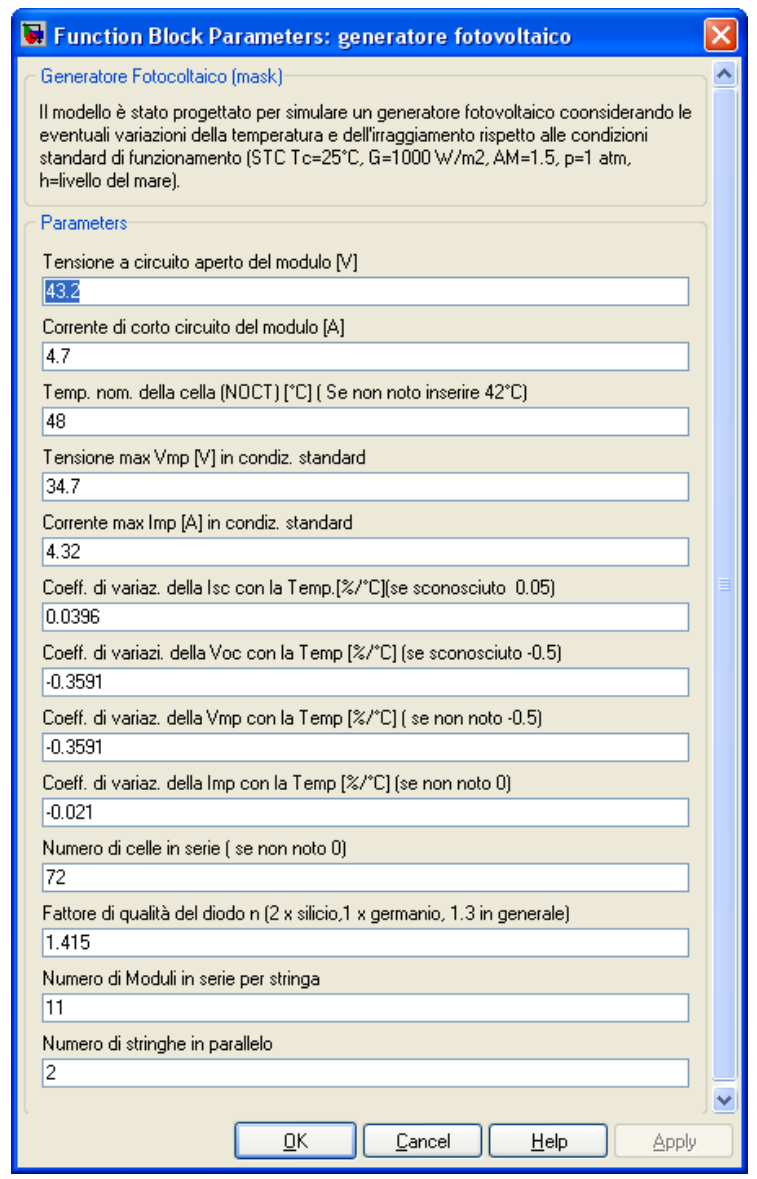

Fig. 3. Mask of the input data of each sub-array.
The dependence of the I-V curve from the temperature is taken into account by means of the thermal coefficients $\alpha$ and $\beta$ with respect to the Standard Test Conditions (STC), stated as $\mathrm{G}_{0}=1000 \mathrm{~W} / \mathrm{m}^{2}, \mathrm{~T}_{0}=25^{\circ} \mathrm{C}, \mathrm{AM}=1.5$. Instead, the dependence of the $\mathrm{I}-\mathrm{V}$ curve from the radiation is quasi-linear with respect to $G_{0}$. Fig. 4 reports the Simulink model implemented to trace the IV-curves as temperature varies (with fixed radiation) or as radiation varies (with fixed temperature).

The proposed model considers also the MPPT (Fig. 2), for which standard Perturbe and Observe (P\&O) algorithm has been implemented, considering that the rated power of the PV plant is $20 \mathrm{kWp}$. In fact $\mathrm{P} \& \mathrm{O}$ algorithm is usually used for small power PV plants, whereas the incremental conductance strategy is implemented for large power PV plants. It has been chosen a coupling capacitor with $\mathrm{C}=2 \mu \mathrm{F}$, which guarantees a maximum value of $5 \%$ of the voltage ripple for each sub-array.

Simpowersystem is a Simulink library containing some power electronic devices. It contains also the models of inverters; then the three-phase inverter model has been chosen and the specifications of Tab II have been imposed.

The filter in $\mathrm{AC}$ is an inductor with $\mathrm{L}=30 \mathrm{mH}$, which guarantees an harmonic distortion less than $2 \%$, as requested by the international technical rule. The insulation transformer has 1:1 ratio. Finally, the interface protection device has been modeled as breakers which power down the PV plant when the grid voltage or the grid frequency exceeds the ranges reported in Fig. 5, as requested by [5] and by the local energy utility company. They imposes that the grid voltage is in the range $\left[0.85 \mathrm{~V}_{\mathrm{n}} \div 1.1 \mathrm{~V}_{\mathrm{n}}\right]$ and that the grid frequency is in the range $[49.7 \div 50.3] \mathrm{Hz}$. This last constraint can be extended for specific situations to $[49 \div 51] \mathrm{Hz}$. Fig. 5 is just the mask of the Function Block representing the interface protection device, which can be modified before running the simulation. In order to link the PV plant to the grid it is needed to synchronize the voltage of the PV plant with the grid voltage; for this aim a standard Phase Looked Loop (PLL), which is a circuit comparing two frequencies, has been implemented.

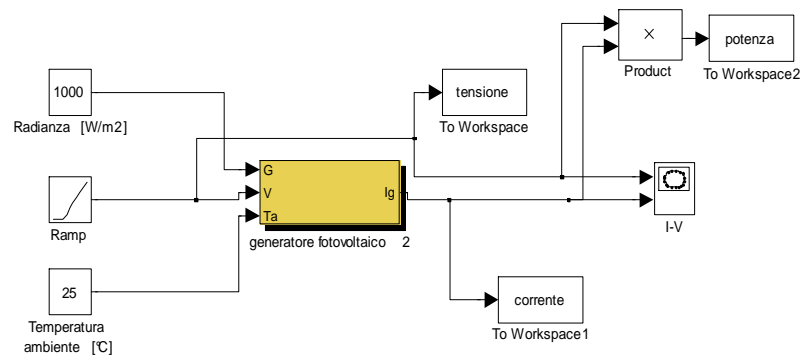

Fig. 4. Simulink model to trace I-V curves. 


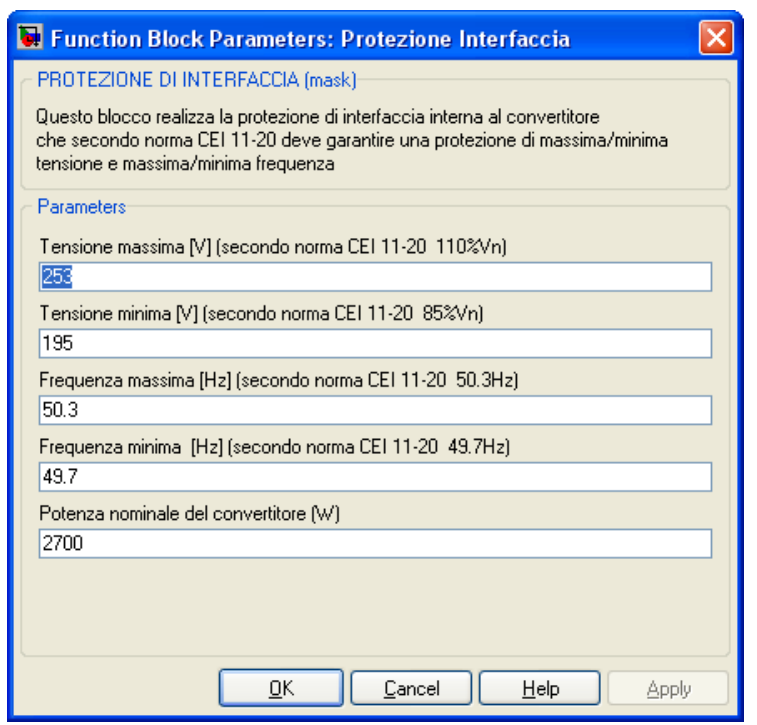

Fig. 5 Thresholds of grid voltage and grid frequency.

\section{Results}

After modeling the PV plant, some simulations have been run in Simulink environment in order to evaluate the goodness and the accuracy of the implemented model. Fig. 6 reports the I-V curves for several values of radiation and fixed environment temperature $\left(\mathrm{Ta}=25^{\circ} \mathrm{C}\right)$. It can be noted that the variation of the radiation $\mathrm{G}$ has different effect on $I_{s c}$ and $V_{o c}$ : the value of $I_{s c}$ is proportional to $G$, while the value of $\mathrm{V}_{\mathrm{oc}}$ has only small deviation with respect to the value in STC.

Fig. 7 represents the I-V curve for several values of the temperature and fixed radiation $\left(\mathrm{G}=500 \mathrm{~W} / \mathrm{m}^{2}\right)$. It can be noted that all the specifications of the PV sub-array are satisfied, remembering that the sub-array is constituting by 2 parallel-connected strings, each one of them constituted by 11 series-connected modules. Also in this case the effect of the temperature variation is different for $I_{s c}$ and $\mathrm{V}_{\mathrm{oc}}$. The first one shows very little variations, whereas $\mathrm{V}_{\mathrm{oc}}$ is more sensible, as expected.

Fig. 8, instead, represents the P-V curve for several values of the radiation. Also in this case the proposed model is able to represent the behavior of the PV subarray, as requested by the technical specifications.

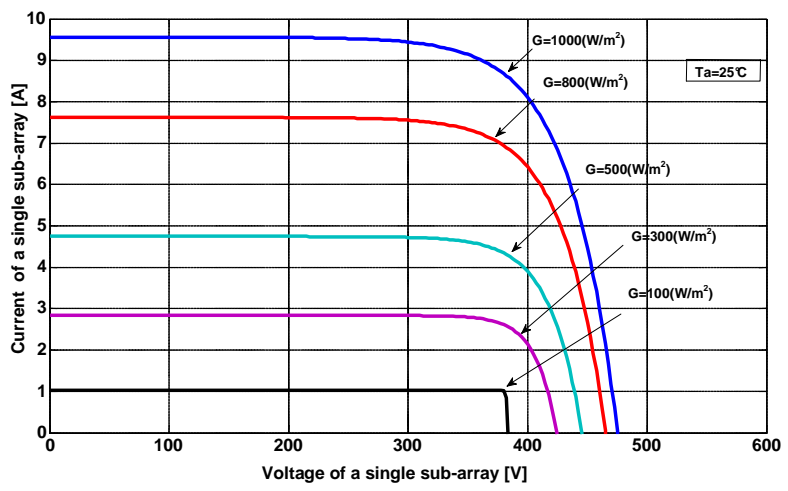

Fig. 6. I-V curves for fixed environment temperature

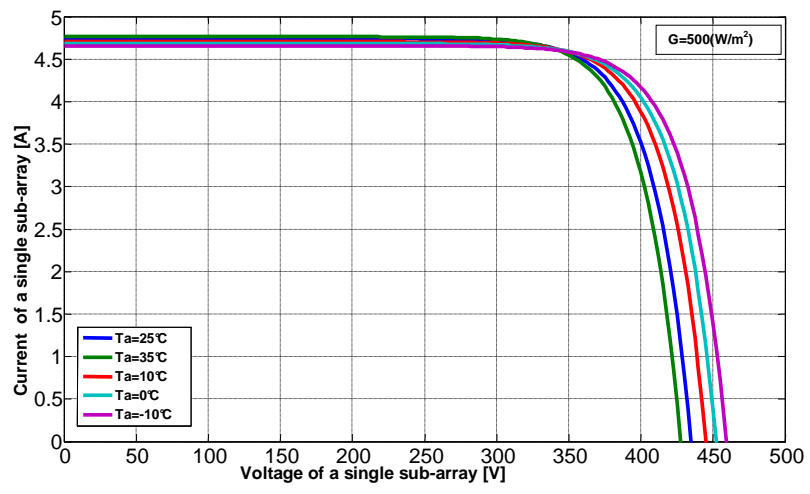

Fig. 7. I-V curves for fixed radiation

In order to study the operation of the interface protection device, an overvoltage equals to $1.5 \mathrm{~V}_{\mathrm{n}}$ has been imposed to the line voltage of the inverter $\mathrm{n}$. 1, starting at the instant $\mathrm{t}=0.2 \mathrm{~s}$ and stopping at the instant $\mathrm{t}=0.3 \mathrm{~s}$ (Fig. 9 . a)).

Fig. 9.b) diagrams the current of the first phase of the inverter $\mathrm{n}$. 1. It can be noted that the current is not zero at the instant $\mathrm{t}=0.2 \mathrm{~s}$, because the technical rule [6] sets a delay time for the opening of the breakers. For the same reason, the closing of the breakers after the end of the overvoltage $(\mathrm{t}=0.3 \mathrm{~s})$ is delayed. Then, the current is still zero for a small time after the end of the overvoltage. Both of them have been also implemented in the model.

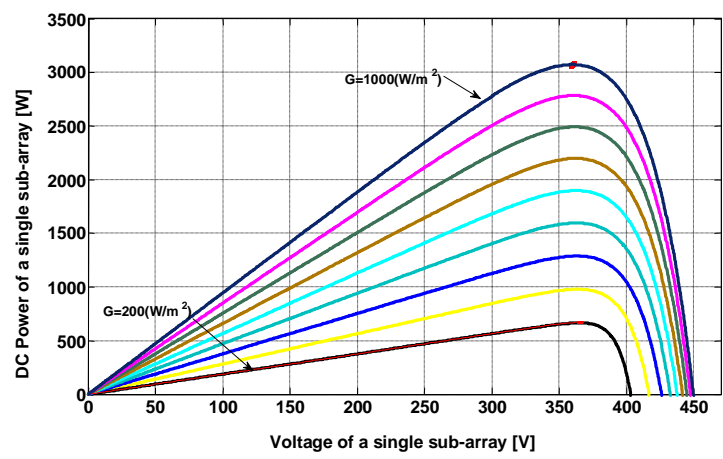

Fig. 8. P-V curves for several values of the radiation

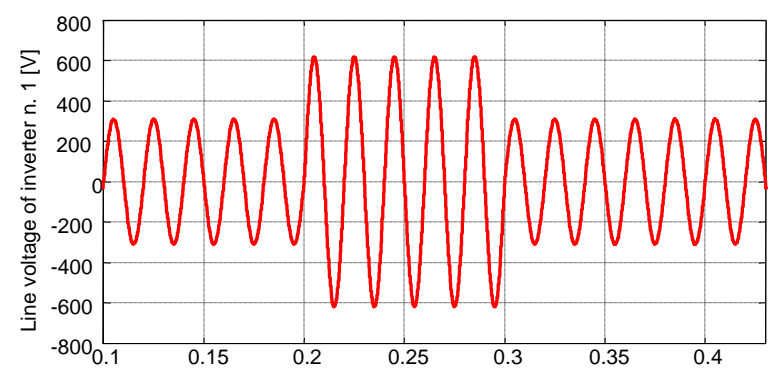

a)

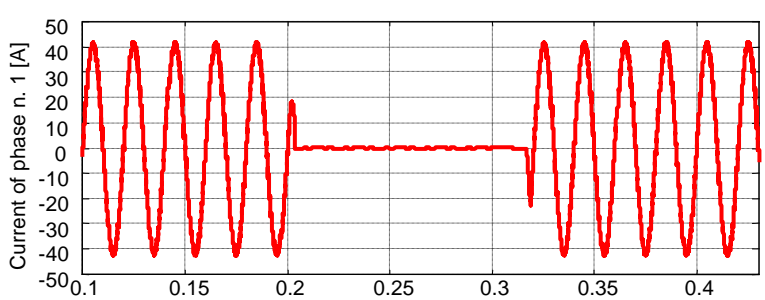

b)

Fig. 9. a) Line voltage of the inverter n.1; b) Line current of the first phase of the inverter $n .1$ 


\section{Conclusions}

The paper has proposed a Simulink based model of a three-phase grid-connected PV plant. The model is based on a real $20 \mathrm{kWp}$ PV plant, but many parameters can be set by the user by means of the masks of several Function Blocks; then it can be also used for very large PV plants with any number of inverters as well as for very small PV plants. Also the values of the coupling capacitor and the Lfilter can be set for any PV plant as well as the thresholds of the interface protection device. The simulations agree with the expected values and allow to study the operation of a PV plant also under real environmental conditions. In fact the input excitation data, constituted by the environment temperature and the radiation, can be imposed utilizing the function "load data". The proposed model can be used as a basis for implementing detailed models of other single parts of PV plants.

\section{References}

[1] Commission of the european communities, GREEN PAPER - A European Strategy for Sustainable, Competitive and Secure Energy, 2006, http://europa.eu/documents/comm/green_papers/pdf/com 2006_105_en.pdf

[2] J. T. Bialasiewicz, "Renewable Energy Systems With Photovoltaic Power Generators: Operation and Modeling”, IEEE Trans. on Industrial Electronics, Vol. 55, Issue 7, 2008, pp. 2752-2758.

[3] M. Ciobotaru, T. Kerekes, R. Teodorescu, A. Bouscayrol, "PV inverter simulation using MATLAB/Simulink graphical environment and PLECS blockset"

[4] M. E. Ropp, S. Gonzalez, "Development of a MATLAB/Simulink Model of a Single-Phase GridConnected Photovoltaic System", IEEE Trans. on Energy Conversion, Vol. 24, Issue 1, 2009, pp. 195-202.

[5] CEI 82-25, Guide to the realization of photovoltaic generation systems connected to the electricity grids of medium and low voltage, 2010.

[6] IEC 1727, Photovoltaic (PV) systems - Characteristics of the utility interface, 2004. 